\title{
Drug use and possession, emerging of new psychoactive substances in the West Bank, Palestine
}

\author{
Basma Damiri $^{1 *} \mathbb{D}$, Wasef Sayeh ${ }^{2}$, Mahran Odeh $^{2}$ and Haytham Musmar ${ }^{2}$
}

\begin{abstract}
Background: The use of illicit drugs has seen an upswing during the last years in the West Bank. Political, social, economic, and demographic factors may play roles in the increasing use of illicit drugs in the West Bank. This study aimed to describe drug possession among Palestinians in order to provide insight into the extent of illicit substances use, to assess their risk, and to explore new forms in order to raise awareness of these drugs. Files (3674) related to drug possession in Anti narcotic drug departments in the West Bank from 2010to 2014 were reviewed and analysed.

Results: Most arrestees (99\%) were males, (55.9\%) aged 18-<30, (48.8\%) singles, (56.7\%) with a primary level of education, and (81.8\%) had used drugs for a year or more. The most common seized and used substances were cannabis, hashish (74.3\%) and marijuana (15.2\%), followed by synthetic cannabinoids, hydro (26.6\%). MDMA (Ecstasy) was used (3.6\%) more than LSD (3.1\%) and more than heroin and cocaine combined (3.3\%). Liquid methamphetamine was emerged as a new homemade yellow substance, with a street name (GG) that is used for improving libido. Attempts to cultivate marijuana using 31,116 seedlings and seeds were recorded.

Conclusion: Tracking the possession of high-risk drugs and new psychoactive substances in a society is important for policy makers in order to investigate the circumstances and impact of these substances. There is a trend in emerging new psychoactive substances (synthetic cannabinoids), manufacturing a new drug (liquid methamphetamine), and cultivating illegal drugs (marijuana) starting from the year 2013. These results are important for prevention, treatment and control, and for law enforcement in the West Bank. Policies, strategies and action plans in the controlling new substances should be developed taking into account local and regional socioeconomic issues.
\end{abstract}

Keywords: Cannabinoid, Methamphetamine, Marijuana, Toxicity, West Bank, Palestine

\section{Background}

Drug possession and use is a global concern and a number of different legislative changes has been introduced around the world to control this problem. There has been a sizeable increase in the production of illicit drugs throughout the world including the Middle East (Dajani 2012). Important changes in trends and patterns of drug use present new challenges to public health practitioners and program planners (WHO 2000). The use of illicit drugs has seen an upswing during the last years in the West Bank especially in cities close to the Israeli borders where producing,

\footnotetext{
* Correspondence: bdamiri@najah.edu

${ }^{1}$ Medicine \& Health Science Faculty, Drug and Toxicology Division, An-Najah National University, Post Box 7, Nablus, West Bank, Palestinian Territories 0970, Palestine

Full list of author information is available at the end of the article
}

smuggling, and distribution of drugs is notably high as a weak governmental control and surveillance on drugs is noticed. Besides the geographical factors, the socio-demographic and political factors play other roles in the increasing the possession and the use of illicit drugs in the West Bank.

The discussion of illicit drug use by the Palestinian society is filled with emotions and inaccuracies. Their use is associated with social disapproval and stigma. Moreover, until the end of October 2015, there was no Palestinian law on drugs and psychotropic substances in force, since the draft drugs law from 2003 has not passed through the Palestinian Legislative Council until October 2015. Therefore, most Palestinians blame the Palestinian National Authority (PNA) for not establishing an effective law against drug dealers and users and 
enforce it. The PNA believes that the absence of forensic service facilities and equipment for testing, especially for new psychoactive substances (NPS), is a major reason for the lack of legal validity of its justice system while the Palestinian society believes that the PNA needs to make more efforts to combat drug crimes and prosecute offenders. Due to all socio-economic-political factors, drug use and possession took a place among Palestinians and spread among them in the last decades in an ascending phase. Therefore, tracking the use of new psychoactive substances (NPS) in a society is important for policy makers in order to investigate the circumstances and impact of these substances.

High-risk drugs and new psychoactive substances can cause adverse effect of the user including dependence, psychological, or social problems or places the person at a high risk of such harm. The emergence of NPS has become an increasing problem in recent years as they are designed to circumvent legislation and therefore, law enforcement agencies and analytical laboratories are in a permanent state of playing catch up (Smith and Morley 2017). They are mostly synthetic chemicals and many of them are derived from natural products. Although they can be classified by their clinical effects stimulant-type, their toxicity remains to be elucidated. They are available and affordable in many countries and sold under different names including brand names such as Mr. Nice guy, Tripe, Mabsatone, Mastalone and Spice/K2 or under their traditional drug names such as Lysergic acid diethylamide (LSD) or Methylenedioxymethamphetamine (MDMA) Ecstasy. As a result, many users do not know exactly what NPS they have used (Feng et al. 2017). Synthetic cannabinoids constitute the majority of NPS items and analogues of $\Delta 9$-tetrahydrocannabinol from cannabis.

The use of systemic research on substance use is still lacking in the Palestinian Territories. There are few studies that have been conducted in the West Bank, East Jerusalem, and Gaza in order to determine the extent of drug use among Palestinians (Massad et al. 2016; Stulhofer et al. 2016; Damiri et al. 2018). To the authors' best knowledge; there are no studies that have described illicit drug possession in Palestine. Studying drug possession can provide insight into the extent of illicit substance use and can assess the risk of these drugs, and explore new forms in order to raise awareness of these drugs. This study is a part of ongoing studies that aim to achieve a comprehensive understanding of the extent of the drug use and possession among Palestinians. The overall objective of this study was to provide insight into the extent of illicit substance possession among Palestinians in the West Bank. Specifically, it aimed to explore the main high-risk possessed drugs and users and their characteristics and trends in drug use and possession.

\section{Methodology}

\section{Data source}

Data analysed in this study were derived from files of persons convicted of illegal drug possession in all anti-narcotic departments in the West Bank from the year 2010 to 2014. This includes illegal drug possession, manufacturing of new illegal drugs, and marijuana cultivation. Confidentiality was assured by keeping the data in a safe place and by using codes instead of names.

\section{Variables}

Variables related to the person convicted of drug possession: Age, place of living, type of work, place of work, level of education, marital status, number of years of using drugs and type of drug used, and previous drug accusation. Variables related to the seized illegal drug: Type of illicit drug seized, weight, number of pills or seeds or seedlings. Hydro here means synthetic cannabinoids in all different market names in the West Bank such as Mr. Nice guy, Spice/K2, Mabsatoon, Mastaloon, Eve, Mariam, and Joker.

\section{Data analysis}

Statistical Product and Service Solutions (SPSS) (version 16. IBM Corporation) was used for data entry and analysis. Variables were described using means, standard deviations, and percentages wherever appropriate.

\section{Ethics}

The study was carried out in accordance with the ethical standards, Declarations of Helsinki. Approval was obtained from Institutional Review Board (IRB) at An-Najah National University in Palestine prior to the research conduction and the general police department approval was obtained. Confidentiality was assured by keeping the data in a safe place and by using codes instead of names. All the information were available for the research team only.

\section{Results}

From the year 2010 to 2014, there were 3674 cases of drug possession in all anti-narcotic departments in the West Bank. Most drug- possession cases were reported in the North of the West Bank $(43 \%, n=1576)$ followed by the Center $(35 \%, n=1271)$ and then the South $(22 \%$, $n=827$ ) with sharp increase in number of cases in the years 2013-2014 (Additional file 1).

\section{General characteristics}

About 99\% of persons convicted with drug possession were young males, $1.9 \%$ were in the age group $<18$ years, and the majortiy $(59.6 \%)$ in the age group $18-30$ years (Table 1). 
Table 1 Age distribution of captured persons with seized substances

\begin{tabular}{|c|c|c|c|c|c|c|c|c|c|c|}
\hline \multirow[t]{3}{*}{ Age group } & \multicolumn{10}{|l|}{ Year } \\
\hline & \multicolumn{2}{|c|}{$2010(\mathrm{no}=648)$} & \multicolumn{2}{|c|}{$2011(\mathrm{no}=601)$} & \multicolumn{2}{|c|}{$2012(\mathrm{no}=605)$} & \multicolumn{2}{|c|}{$2013(\mathrm{no}=851)$} & \multicolumn{2}{|c|}{$2014(\mathrm{no}=969)$} \\
\hline & no & $\%$ & no & $\%$ & no & $\%$ & no & $\%$ & no & $\%$ \\
\hline$<18$ & 18 & 2.8 & 13 & 2.2 & 8 & 1.3 & 16 & 1.9 & 13 & 1.3 \\
\hline $18-<30$ & 305 & 47.1 & 328 & 54.6 & 332 & 54.9 & 509 & 59.8 & 578 & 59.6 \\
\hline $30-40$ & 211 & 32.6 & 162 & 27.0 & 162 & 26.8 & 213 & 25.0 & 252 & 26.0 \\
\hline $41-65$ & 100 & 15.4 & 87 & 14.5 & 92 & 15.2 & 99 & 11.6 & 112 & 11.6 \\
\hline$>65$ & 0 & 0.0 & 1 & 0.2 & 3 & 0.5 & 1 & 0.1 & 0 & 0.0 \\
\hline Missing data & 14 & 2.2 & 10 & 1.7 & 8 & 1.3 & 13 & 1.5 & 14 & 1.4 \\
\hline Total & 648 & 100 & 601 & 100 & 605 & 100 & 851 & 100 & 969 & 100 \\
\hline
\end{tabular}

According to level of education, most of them (56.7\%) with primary level, and $30.3 \%$ with high school level, while $0.8 \%$ were illiterate (Table 2). Around $90.1 \%$ of them were Palestinian from the West Bank and 7.5\% were Palestinian with Israeli nationality, $49 \%$ were singles, $3.0 \%$ were students, $72.3 \%$ were workers, $64.4 \%$ work in the West Bank and $33.2 \%$ work in Israel. Around $76.5 \%$ of the suspected persons with seized illicit drugs are currently drug users and around $82.1 \%$ of them have used drugs for 1 year or more, and $47 \%$ of them had convicted previous offenses at least once in their lifetime. Most of the suspected persons (79.2\%) live in the West Bank: $45.7 \%$ in cities, $37.6 \%$ in villages and $9.6 \%$ in refugee camps (Table 2). Moreover, $76.3 \%$ live in the same governorate where the substances were seized with more cases in cities than in villages and refugee camps.

\section{Classification of seized and used drugs}

The most common substance seized in relation to both the number of cases (88.7\%) and all seized substances $(68.3 \%)$ is cannabis in forms of hashish $(56.3 \%)$, and marijuana (5.8\%) followed by synthetic cannabinoids (hydro; 26.6\%) (Table 3). Around 14\% of seized substances were pills. MDMA (ecstasy) was the most common seized $(6.8 \%)$ followed by LSD (3.1\%) and other prescribed pills such as benzodiazepam (i.e. clonex) (2.0\%), tramadol $(0.6 \%)$, diazepam (i.e. assival) $(0.5 \%)$, and methadone $(0.2 \%)$. Cocaine was seized more than heroin ( $2.8 \%$ and $1.7 \%$; respectively). Non-specific drugs here are either substances or pills that were not identified in anti-narcotic center before sent to be analysed in the forensic lab at the time they were seized. A homemade yellow liquid samples were seized under a street name called GG and as alternative to sildenafil (Viagra). The liquid was analysed and reported as homemade liquid methamphetamine.

The based weights of the substances were as the following: Hydro $(51.53 \mathrm{Kg})$ was the most seized followed by hashish $(43.84 \mathrm{Kg})$, marijuana $(32.09 \mathrm{Kg})$, heroin $(2.82 \mathrm{Kg})$, khat $(2.3 \mathrm{Kg})$, and finally cocaine $(0.29 \mathrm{Kg})$. Based on number and type of pills, ecstasy was most seized (10,219 pills) followed by LSD (2444), clonex

Table 2 Socio-demographic data of suspected persons captured with seized substances

\begin{tabular}{|c|c|c|c|c|c|c|c|}
\hline Level of education & no (\%) & occupation & no (\%) & Place of Work & no (\%) & Place of living & no (\%) \\
\hline Illiterate & $29(0.8)$ & Workers & $2653(72.3)$ & West Bank & $2028(64.4)$ & West Bank & $2909(79.2)$ \\
\hline Primary & $2083(56.7)$ & Students & $110(3)$ & Israel & $1046(33.2)$ & Jerusalem & $402(10.9)$ \\
\hline High school & $631(30.3)$ & Employee & $136(3.7)$ & Others & $5(0.2)$ & Israel & $277(7.5)$ \\
\hline Undergraduate & $331(9)$ & Unemployed & $316(8.6)$ & & & Others & $29(0.8)$ \\
\hline Graduate & $11(0.03)$ & Others & $353(9.6)$ & & & & \\
\hline Missing data & $589(16.1)$ & Missing data & $107(2.9)$ & Missing data & $68(2.2)$ & Missing data & $57(1.6)$ \\
\hline Years of drug use & no (\%) & Drug addiction & no (\%) & $\begin{array}{l}\text { Previous conviction } \\
\text { of second or } \\
\text { subsequent offenses }\end{array}$ & no (\%) & Marital Status & no (\%) \\
\hline$<1$ & $504(17.9)$ & Yes & $2810(76.5)$ & Yes & $1281(34.9)$ & Single & $1793(48.8)$ \\
\hline $1-<5$ & 1007 (35.8) & No & $469(12.8)$ & No & $2015(54.8)$ & Married & $1734(47.2)$ \\
\hline $5-10$ & $635(22.6)$ & & & & & Others & $74(2)$ \\
\hline$>10$ & $470(16.7)$ & & & & & & \\
\hline Missing data & $194(6.9)$ & Missing data & $395(10.8)$ & Missing data & $378(10.3)$ & Missing data & $74(2)$ \\
\hline
\end{tabular}


Table 3 Type of possessed substances in relation to the number of cases and in relation to all seized substances in the West Bank across the years 2010-2014

\begin{tabular}{|c|c|c|c|}
\hline \multirow[t]{2}{*}{ Seized substances } & \multirow{2}{*}{$\begin{array}{l}\text { Seized substances } \\
\text { in relation to the } \\
\text { number of cases } \\
\text { no (\%) }\end{array}$} & \multicolumn{2}{|c|}{$\begin{array}{l}\text { Seized substance in } \\
\text { relation to all seized } \\
\text { substances }\end{array}$} \\
\hline & & $\overline{\text { no }}$ & $\begin{array}{l}\text { Based Weight } \\
\text { in } \mathrm{gm} \text { or } \mathrm{n}^{\mathrm{a}}\end{array}$ \\
\hline Hashish & $2068(56.3)$ & 1704 & $43,844.32$ \\
\hline Marijuana & $213(5.8)$ & 181 & $32,086.27$ \\
\hline Hydro & $977(26.6)$ & 835 & $51,526.6$ \\
\hline Cocaine & $63(1.7)$ & 57 & 290.8 \\
\hline Heroin & $104(2.8)$ & 92 & 2823.5 \\
\hline Ecstasy & $251(6.8)$ & 221 & $10219^{a}$ \\
\hline Tramadol & $21(0.6)$ & 19 & $388^{\mathrm{a}}$ \\
\hline Clonex & $72(2.0)$ & 58 & $740^{\mathrm{a}}$ \\
\hline Assival & $20(0.5)$ & 18 & $465^{\mathrm{a}}$ \\
\hline Methadone & $6(0.2)$ & 5 & $52^{\mathrm{a}}$ \\
\hline LSD & $113(3.1)$ & 105 & $2440^{\mathrm{a}}$ \\
\hline Seeds and seedlings & $84(2.3)$ & 79 & $31116^{\mathrm{a}}$ \\
\hline Khat & $10(0.3)$ & 9 & 2309.2 \\
\hline${ }^{\mathrm{b}}$ Non-specific substance & $13(0.4)$ & 10 & $371^{\mathrm{a}}$ \\
\hline 2 or more substances & 1031(28.1) & & \\
\hline Total & $3674(100)$ & 3979 & \\
\hline
\end{tabular}

${ }^{a}$ numbers of seized pills

${ }^{b}$ Non-specific: new form substances that were not recognized at the time of the capturing and were sent to the forensic lab to be identified

(740), assival (465) and tramadol (388) and lastly methadone (52). Eighty-four reported cases of cultivation of marijuana were reported with 31,116 seeds and seedlings of cannabis. Around $28.1 \%$ of the suspected had possessed two or more substances at the same time.

About $76.5 \%$ of the captured persons with seized substances were drug users and $34.9 \%$ of them were captured previously with seized illicit substances (Table 2). The most frequent drug that had been used was cannabis, hashish (74.3\%) and marijuana (15.1\%) either alone or as a part of combination followed by synthetic cannabinoids, hydro (26.6\%) (Table 4). Cocaine or heroin alone were more used than ecstasy alone while in a combination with other drugs, ecstasy was more used than cocaine and heroin. In addition to that, $5.3 \%$ of users use three or more drugs at the same time (Table 4).

Besides being the most used, hashish was the most dominant drug seized (68.4\%) until the year 2013. A sharp decrease in natural cannabinoids, hashish and marijuana, use and possession in the years 2013 and 2014 was reported in favor to a sharp increase in the used and seized synthetic cannabinoids, hydro (Fig. 1). In general, there was a clear trend of using synthetic cannabinoids and liquid amphetamine starting from the year 2013 in prefer to other used or seized substances (Fig. 1).

\section{Discussion}

The problem of illicit drug use has markedly increased through the recent years among Palestinian population. This study has explored risk of drug possessions on the Palestinian society in two main aspects, socially and mentally. These factors include the age of the drug users, their level of education, the type and the duration of using illicit drugs, and combination of illicit drugs use. These factors can assess the danger of this problem on the Palestinian society.

A survey done by the National Survey of Drug Use and Health (NSDUH) in 2013 demonstrated that the highest percentage of those who use illicit drugs in USA fall in the age category of 18-25 years. In this study, the majority $(55.9 \%)$ of drug users and possessors were young adult males $(18-<30$ years). This age is considered to be the age of pursuing high education and marriage in the Palestinian society. Most of the suspected were singles, workers, and with low level of education as $56.7 \%$ of them had finished only primary school and $3.5 \%$ were students at the time of the study. Only 9\% had finished bachelor degrees. In fact, there was a sharp decrease in the number of drug users with increasing the level of education. In a study done in Iran, 39\% of illicit drug users were illiterate or had primary education compared to only $5.3 \%$ of the none users group (Naserzadeh 2013). Attention should be paid through social media and educational campaigns to the role of school dropout in this problem.

Globally, cannabis is probably the most widespread and commonly used illicit drug (WHO 2000). According to the World Drug Report in 2014, an estimation of $3.8 \%$ of the general population of the world has used cannabinoids as illicit drugs (UNDOC 2014). In most countries, rates of cannabis use are generally higher in younger adults, and higher amongst males than females (WHO 2000). In the United States, there was a 59\% increase in cannabis-related emergency visits and a $14 \%$ increase in cannabis-related treatment admissions (SERVICES 2014). Cannabis use is responsible for $0.8 \%$ of disability adjusted life years worldwide in 2010 (UNDOC 2014). Similar to other parts of the world, cannabinoids, either natural or synthetic, were the most commonly illicit drug seized and used in the West Bank in the years 2010-2014. The cause of this high frequency of cannabis use among drug users may be contributed to its relatively low price when compared to other illicit drugs and the availability of their products (Damiri et al. 2018). Moreover, most drug users had initiated drug use in their adolescence making them at higher risk for the psychosocial complications of cannabis drug use (Chadwick et al. 2013). There is a strong evidence of the major negative impact of the initiation of cannabis use in early age (UNDOC 2014). The initiation and use among youth 
Table 4 Substances used by suspected persons captured with seized substances in the years 2010-2014

\begin{tabular}{|c|c|c|c|c|}
\hline$N=2810$ & Used substances & no (\%) & Used substances & no (\%) \\
\hline \multirow[t]{2}{*}{ Cannabis } & Hashish & $1192(42.4)$ & Hashish all & $2088(74.3)$ \\
\hline & Marijuana & $75(2.7)$ & Marijuana all & $425(15.2)$ \\
\hline Synthetic cannabinoids & Hydro & $299(10.6)$ & Hydro all & $748(26.6)$ \\
\hline \multirow[t]{3}{*}{ Amphetamine-type stimulants } & Ecstasy & $15(0.5)$ & Hashish+Marijuana & $340(12.1)$ \\
\hline & Ecstasy All & 101(3.6) & Hashish+Hydro & $439(15.6)$ \\
\hline & Non-specific drugs & $18(0.6)$ & Marijuana+Hydro & $10(0.4)$ \\
\hline \multirow[t]{3}{*}{ Prescribed drugs } & Tramadol & $7(0.2)$ & Hashish+Cocaine & $33(1.2)$ \\
\hline & Clonex & $5(0.2)$ & Hashish+Ecstasy & $84(3.0)$ \\
\hline & Assival & $3(0.1)$ & Khat & $7(0.2)$ \\
\hline \multirow[t]{2}{*}{ Opioids } & Heroin & $29(1.0)$ & 3 or more substances & $150(5.3)$ \\
\hline & Methadone & $1(0.0)$ & Missing Data & $69(2.5)$ \\
\hline \multirow[t]{2}{*}{ Cocaine } & Cocaine & $33(1.2)$ & & \\
\hline & Cocaine all & $66(2.3)$ & & \\
\hline
\end{tabular}

and young adults is of particular concern due to the established increased risk of harm such as other drug use and dependent drug use, a risk of heavy dependence, lung problems, memory impairment and psychosocial problems (UNDOC 2014). Taking into account that most of the drug users were young adults, $81.1 \%$ of the users had illicit drug for more than 1 year and $5.3 \%$ of them had used two or more substances at the same time indicating that they were addict. In fact, 39.3 and 16.7\% had used illicit drugs for more than 5 or 10 years; respectively. Emerging evidence also suggests that heavy cannabis use by adolescents increases the risk of depression and schizophrenia in later life, especially in individuals who already have a vulnerability to develop a psychiatric syndrome (Radhakrishnan et al. 2014; Chadwick et al. 2013).
Moreover, there is an increase in trials to produce these drugs locally. Cannabis cultivation emerged in 2013 and 2014 indicating that the young adults are implicated in the field of drugs farming, marketing and abusing. This signifies the burden of cannabinoids use on the personal and governmental levels through the money wasted on cannabinoids use and its implications on health and economy (Arseneault et al. 2002).

Many studies had demonstrated the health effect of synthetic cannabinoids (2010, Every-Palmer 2010). These side effects are not similar to those caused by the use of natural cannabinoids and may indicate the presence of potential synthetic additives and toxicants that cause these symptoms (Willey 2009). A sharp decrease in the numbers of both hashish users and cases with seized

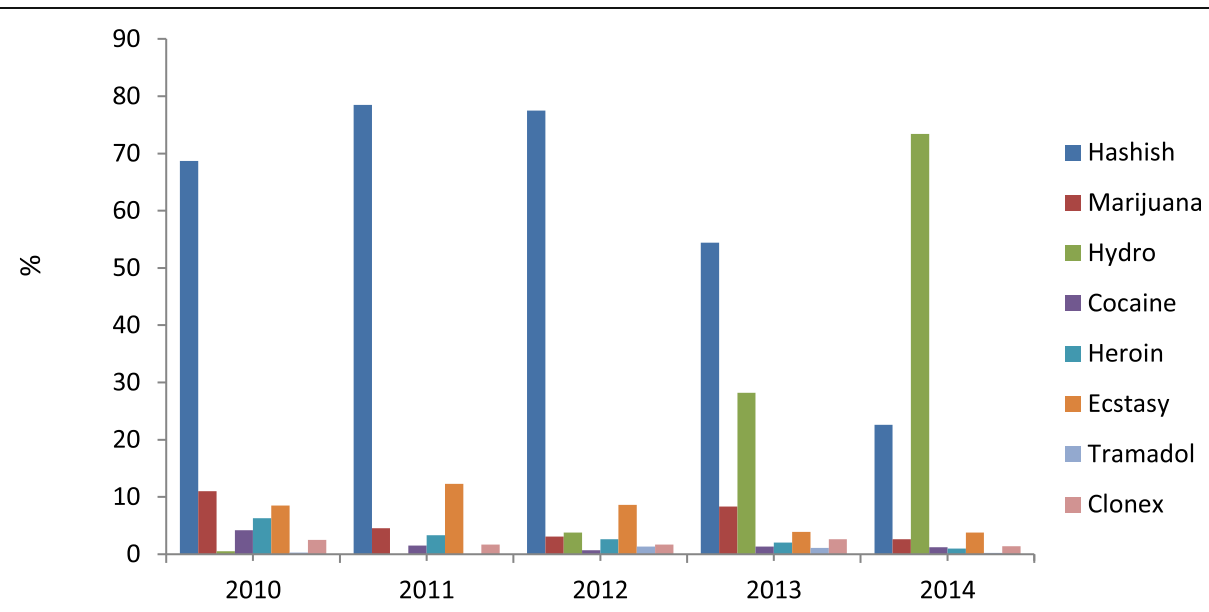

Fig. 1 The most frequent seized substances in relation to number of cases in the West Bank in the years 2010-2014. Natural cannabinoids, hashish and marijuana, were the most common sized substances followed by synthetic cannabinoids, hydro. A sharp decrease in the numbers of both hashish users and cases with seized natural cannabinoids, hashish and marijuana, had been recorder in the years 2013 and 2014 in favor to a sharp increase in the used and seized synthetic cannabinoids, hydro 
hashish had been recorder in the years 2013 and 2014 in favor to a sharp increase in the used and seized hydro. Hydro is a powerful synthetic drug which mimics marijuana but more potent and more dangerous as the addiction rate is higher and long-term health effects are unknown. The use of synthetic cannabinoids in the West Bank is magnified by the fact that synthetic cannabinoids are substandard and counterfeited in certain cities in the West Bank. Synthetic cannabinoids are mixed with tobacco and with other more toxic compounds as insecticides, rodenticides and acetone to make more potent substance for a lower price. The number of cases of seized illicit drugs varied between the West Bank governorates. The closer to the Israeli borders; such as Tulkarm and Qalqilya, and to Jerusalem such as Ramallah, the more cases were reported. Producing, smuggling, and distribution of drugs are notably high in these cities compared to others due to weak governmental control and surveillance on drugs in these cities. These cities are also considered passage points for Palestinian workers who work in Israel. Around $90.1 \%$ of the arrestees were young workers aged 18-30 years. Around $64.4 \%$ of the workers work in the West Bank and (33.2\%) work in Israel. Among factors acting in favor of the increasingly extensive use of synthetic cannabinoids drug category in the year 2014 are the lack of appropriate surveillance and regulations in these cities and the rapid development and shorter time to launch on the market and therefore the lower price, resulting in higher availability and accessibility, particularly for young adults (Damiri et al. 2018). Therefore, more governmental control and surveillance on drugs in these cities is required. Therefore, the trend of increased use of substandard or falsified synthetic cannabinoids in the West Bank is of particular concern and action should be taken to face this problem.

The use of amphetamine-type stimulants (ATS) is a global and growing phenomenon, typically involving amphetamine and methamphetamine, but also amphetamine analogues of the MDA-type including MDMA or (ecstasy)(WHO 1997, 2018). Patterns of ATS use in appear to have been cyclical, with increasing trends of use and related problems accumulating to a critical level that results in widespread awareness of those problems and a consequent dramatic drop in usage in many countries (WHO 1997, 2018). Seized pills constituted about 14\% of all cases. Ecstasy was the most frequent seized pill (6.8\%). In recent years, there has been a pronounced increase in the production and use of ATS world-wide (UNDCP 2000). Non-specific drugs here in this study are either substances or pills that were not identified in anti-narcotic center before sent to be analyzed in the forensic lab at the time they were seized. Forensic science is new in Palestine and was established by the coming of the Palestinian National Authority in 1994. It suffers from a shortage of staff, components, and laboratories. The forensic laboratories have started working in 2016 . Before the year 2016, the type of seized substance herein depends on what the accused person confessed and on the experience of the investigators in the narcotic drugs involved. In the event that the accused person did not confess the type of substance or the substance is suspected of being a new in the drug market, it is classified under Non-specific drugs. In any case, the substances used to be analyzed in An-Najha National University Biochemistry and Toxicology Laboratories and the Ministry of Health Laboratories to confirm its type. A homemade yellow liquid substance that was seized under a street name called GG and as alternative to Sildenafil (Viagra). This new form substance tends to occur most frequently in groups that engaged in risky behaviors. It was claimed by this substance makers that this substance is used for increasing libido. Toxicological testing of users' urine was positive for methamphetamine compared to none users. The substance was subjected to further methamphetamine testing. Interviews for both the users and the substance makers were conducted. The liquid was reported as homemade liquid methamphetamine. A legislative change was introduced concerning this substance. The use and the synthesis of this illicit drug has seen an upswing during the last years in cities close to the Israeli borders where producing, smuggling, and distribution of drugs is notably high. Among factors acting in favor of the use and the synthesis of this homemade substance are the rapid development and shorter time to launch on the market and therefore the lower price, and the lack of analytical and clinical experience in discovering new homemade drugs, resulting in higher availability and accessibility, particularly for young adults.

Opioids are considered the main drug type that is implicated in drug-related deaths in the World (UNDOC 2014). A large proportion of these deaths are contributed to drug overdose, which can lead to sudden cardiac and respiratory arrest. Despite that, many of them can be contributed to the mode of drug intake (Gambaro et al. 2014; Guerrini et al. 2013). The use of opioids is relatively higher in the Southern part of the West Bank (5.7\% total in the last 5 years) compared to the Northern (1.5\%) and the Center (3\%). One of possible causes may be related to the close proximity of the south from the desert making it easily feasible to drugs coming from Egypt, Beer il Sabe' and Gaza.

The weak governmental control and surveillance on writing prescriptions for narcotics in the years before 2016 could explain the increased level of seized pills. A number of drugs used commonly for their therapeutic efficacy in health care are also being misused all over the world. These include barbiturates, benzodiazepines, other 
sedatives and some stimulant drugs. There must be strong regulations on the medical uses of medications that have dependence potential such as Tramadol, Diazepam (Assival), and Benzodiazepam (Clonex).

It's known that drug dependency is a multifactorial issue which relies on the duration of drug use, the type of the material used and the genetic susceptibility of the user (NIH 2007). A previous study was conducted by the United Nations Office on Drugs and Crime (UNODC) on drug users in Palestine based on personal interviews with some drug users who were found to use drugs on daily bases (UNDCP 2000). Most drug users (82.1\%) have used drugs for more than 1 year, $39.3 \%$ had used drug for more than 5 years, (47\%) were convicted of second or subsequent offenses, and (28.1\%) of the cases use two or more illicit drugs. Using two or more illicit drugs is of great significance due to the potential harmful effects of some drug combinations that can lead to hazardous and sometimes deadliest results. The long duration of drug use and the recurrence of the arrest call for deterrent Palestinian law against drugs possession and drug use. The illicit drug law in the West Bank was managed with the Jordanian law that was established in the West Bank in 1955 and it was modified in 1975 (Kordi 2014). This law is considered out of date regarding the new technical and pharmaceutical updates related to illicit drugs and drug use. It is also considered to be in the favor of drug users and drug dealers and always took the least harmful sentence against criminals. On the other hand, the absence of governmental rehabilitation centers and the high costs for treatment in private ones led to the absence of medical and psychosocial follow up for drug users which contributed to longer periods of drug use. Establishing of governmental rehabilitation centers in the West Bank that provide the psychological, social and medical care of drug addicts is recommended.

\section{Conclusions}

Tracking the possession of high-risk drugs and new psychoactive substances in a society is important for policy makers in order to investigate the circumstances and impact of these substances. There is a trend in emerging new psychoactive substances (synthetic cannabinoids), manufacturing a new drug (liquid methamphetamine), and cultivating illegal drugs (marijuana) starting from the year 2013 in prefer to other used or seized substances. These factors and the ascending character of this problem are important to increase the priorities of all who are interested to combat this problem. These results are important for prevention, treatment and control and for law enforcement in the West Bank. Policies, strategies and action plans in the controlling new substances should be developed taking into account local and regional political and socioeconomic issues.

\section{Additional file}

Additional file 1: Summary of the number of cases of persons captured with seized drugs and substances in each governorate in the West Bank in the years 2010-2014. (DOCX 16 kb)

\begin{abstract}
Abbreviations
ATS: Amphetamine-type stimulants; IRB: Institutional Review Board; LSD: Lysergic acid diethylamide; MDMA: Methylenedioxymethamphetamine; NPS: New psychoactive substances; NSDUH: National Survey of Drug Use and Health; PNA: Palestinian National Authority; SPSS: Statistical Product and Service Solutions; UNODC: United Nations Office on Drugs and Crime
\end{abstract}

\section{Acknowledgements}

We are very grateful to Palestinian Chief of Police and the directors of Anti Narcotic Department, who provided general support. Special thanks to Abdallah Eliewi for his support.

\section{Availability of data and materials}

Data that support the findings of this study and /or analysed during the current study are available from the corresponding author on reasonable request. Most data generated or analysed during this study are included in this manuscript. Other data that support the findings of this study and/or analysed during the current study are available from the corresponding author on reasonable request.

\section{Authors' contributions}

BD wrote the initial draft of the manuscript. All authors contributed to the study design and literature the search, carried out the data collection, analysed the data and prepared data tables. All authors were involved in interrupting the data and had full approval of the submitted and published version. All authors read and approved the final manuscript.

\section{Ethics approval and consent to participate}

The study was carried out in accordance with the ethical standards, Declarations of Helsinki. Approval was obtained from Institutional Review Board (IRB) at An-Najah National University in Palestine prior to the research conduction and the general police department approval was obtained. Confidentiality was assured by keeping the data in a safe place and by using codes instead of names. All the information were available for the research team only.

\section{Consent for publication}

Not applicable.

\section{Competing interests}

The authors declare that they have no competing interests.

\section{Publisher's Note}

Springer Nature remains neutral with regard to jurisdictional claims in published maps and institutional affiliations.

\section{Author details}

${ }^{1}$ Medicine \& Health Science Faculty, Drug and Toxicology Division, An-Najah National University, Post Box 7, Nablus, West Bank, Palestinian Territories 0970, Palestine. ²Department of Medicine, An-Najah National University, Nablus 0970, Palestine.

Received: 27 April 2018 Accepted: 10 July 2018

Published online: 13 July 2018

\section{References}

Arseneault L, Cannon M, Poulton R, Murray R, Caspi A, Moffitt TE (2002) Cannabis use in adolescence and risk for adult psychosis:longitudinal prospective study. BMJ 325(7374):1212-1213

Chadwick B, Miller ML, Hurd YL (2013) Cannabis use during adolescent development: susceptibility to psychiatric illness. Front Psychiatry 4:129

Dajani, T. A. 2012. Substance abuse among Palestinians in the West Bank and Gaza Strip 
Damiri BR, Sandouka HN, Janini EH, Yaish ON (2018) Substance use by university students in the West Bank: a cross-sectional study. Lancet 391(Suppl 2):S9

Every-Palmer S (2010) Warning: legal synthetic cannabinoid-receptor agonists such as JWH-018 may precipitate psychosis in vulnerable individuals. Addiction 105(10):1859-1860

Feng LY, Battulga A, Han E, Chung H, Li JH (2017) New psychoactive substances of natural origin: a brief review. J Food Drug Anal 25:461-471

Gambaro V, Argo A, Cippitelli M, Dell'Acqua L, Fare F, Froldi r, Guerrini K, Roda G, Rusconi C, Procaccianti P (2014) Unexpected variation of the codeine/ morphine ratio following fatal heroin overdose. J Anal Toxicol 38:289-294

Guerrini K, Argo A, Borroni C, Catalano D, Dell'Acqua L, Fare F, Procaccianti P, Roda G, Gambaro V (2013) Development and validation of a reliable method for studying the distribution pattern for opiates metabolites in brain. J Pharm Biomed Anal 73:125-130

Kordi Y (2014) Narcotics crimes and manners of fighting it in accordance with Palestinian jurisprudence "comparative study". An-Najah Univ J Res

Massad SG, Shaheen M, Karam R, Brown R, Glick P, Linnemay S, Khammash U (2016) Substance use among Palestinian youth in the West Bank, Palestine: a qualitative investigation. BMC Public Health 16:800

Naserzadeh M (2013) The mental health and substance abuse among youths aged 18-29: a comparative study. J Educ Health Promot 2:34

$\mathrm{NIH}$, N. I. O. D. A (2007) Drugs, brains and behavior : the science of addiction. National Institute on Drug Abuse

Radhakrishnan R, Wilkinson ST, D'Souza DC (2014) Gone to pot - a review of the association between Cannabis and psychosis. Front Psychiatry 5:54

SERVICES, U. S. D. O. H. A. H (2014) Results from the 2013 National Survey on drug use and health: summary of National Findings. U.S. Department of Health and Human Services, Rockville

Smith PR, Morley SR (2017) New psychoactive substances. In: Rutty GN (ed) Essentials of autopsy practice: reviews, updates, and advances. Springer International Publishing, Cham

Stulhofer A, Jwehan I, Aburabie R (2016) HIV and HCV prevalence and incarceration-related risks among injecting drug users in three West Bank governorates. AIDS Care 28:1159-1165

UNDCP, U. N. I. D. C. P (2000) World drug report. Oxford University Press, New York UNDOC, U. N. O. O. D. A. C. (2014) . Veinna: United Nations Office on Drugs and Crime WHO. (1997). Amphetamine-type stimulants Geneva

WHO (2000) Guide to drug abuse epidemiology. World Health Organization, Geneva WHO. (2018). Management of substance abuse, Amphetamine-type stimulants. Available: http://www.who.int/substance_abuse/activities/amphetamine/en/ Accessed 22 June 2018

Willey J (2009) JMS Letter. J Mass Spectrom

\section{Submit your manuscript to a SpringerOpen ${ }^{\circ}$ journal and benefit from:}

- Convenient online submission

- Rigorous peer review

- Open access: articles freely available online

- High visibility within the field

- Retaining the copyright to your article

Submit your next manuscript at $\boldsymbol{\nabla}$ springeropen.com 